\title{
Cooperativismo em Goiás: como equalizar competitividade e solidariedade?
}

\author{
Cooperativism in Goiás: how to match competitiveness and solidarity?
}

\section{Cooperative a Goiás: comment egaliser competitivite et la solidarite?}

Cooperación en Goiás: cómo coordinar la competitividad con la solidaridad?

\author{
Mauro Pereira Santos ${ }^{1}$ \\ Juliana Rodrigues ${ }^{1}$ \\ Gabriel Medina'
}

Recebido em 23/03/2017; revisado e aprovado em 19/04/2017; aceito em 19/05/2017

DOI: http://dx.doi.org/10.20435/inter.v18i4.1537

\begin{abstract}
Resumo: O artigo trata do desafio de cooperativas de agricultores familiares em serem competitivas no mercado e solidárias junto a seus cooperados. As cooperativas analisadas tiveram diferentes graus de inserção comercial e de eficiência na gestão, mas responderam de forma similar às necessidades dos agricultores cooperados enquanto alternativa de mercado e espaço de fortalecimento das relações sociais.
\end{abstract}

Palavras-chave: cooperativismo; agricultura familiar; desenvolvimento rural; Goiás.

\begin{abstract}
This paper assesses how family farm-based cooperatives deal with the need to be competitive in the market and accountable to its members. The studied cooperatives have varying degrees of commercial integration and management efficiency, but respond in a similar manner to the needs of their members as an alternative for farmers to market their products as well as to strength their social relations.
\end{abstract}

Key words: cooperativism; family farming; rural development; Goiás.

Résumé: L'article traite de la difficulté des coopératives de familles d'agriculteurs à être compétitive sur le marché et la solidarité entre ses membres. Les coopératives analysées avaient des degrés divers de l'intégration commerciale et une gestion efficace, mais a répondu d'une manière similaire aux besoins des agriculteurs des coopératives comme un marché alternatif et le renforcement de l'espace des relations sociales.

Mots-clés: coopération cooperativite; l'agriculture familiale; le développement rural; Goiás.

Resumen: En este artículo se aborda el reto de cooperativas de agricultores familiares en ser competitivas en el mercado y solidarias con sus miembros. Las cooperativas analizadas tienen diversos grados de integración comercial y de eficiencia en la gestión, pero responden de manera similar a las necesidades de los agricultores funcionando como un mercado alternativo y fortalecimiento sus relaciones sociales.

Palabras clave: cooperativismo; agricultura familiar; desarrollo rural; Goiás.

\section{INTRODUÇÃO}

O interesse no desenvolvimento local e no papel que pode ser desempenhado pelas cooperativas está sendo retomado de forma crescente nos últimos anos, em escala internacional (WIGGINS; KIRSTEN; LLAMBÍ, 2010). O Diretor-geral da Organização das Nações Unidas para Alimentação e Agricultura (FAO), José Graziano, afirma que o cooperativismo é uma importante ferramenta para fomentar a agricultura familiar e o desenvolvimento rural no Brasil (ASSOCIAÇÃO NACIONAL DE DEFESA VEGETAL [ANDEF], 2014). Estudos chamam atenção para a capacidade produtiva da agricultura familiar brasileira, que produz grande parte dos alimentos consumidos no país (FRANÇA; DEL GROSSI; MARQUES, 2009).

Considerando o papel estratégico do Estado na promoção da agricultura familiar (ABRAMOVAY, 1992), uma das principais frentes de ação da política federal tem sido na garantia de mercado institucional para os agricultores familiares pelo Programa Nacional de Alimentação

\footnotetext{
${ }^{1}$ Universidade Federal de Goiás (UFG), Goiânia, Goiás, Brasil.
} 
Escolar (PNAE), pelo Programa de Aquisição de Alimentos (PAA) e pelo Programa Nacional de Produção e Uso de Biodiesel (PNPB) (CALDAS; NONATO, 2014). As cooperativas são apontadas como alternativa para a integração comercial dos agricultores familiares tanto nos mercados convencionais quanto nos institucionais (REDIN, 2015; SILVA; SILVA, 2011; ORGANIZAÇÃO DAS NAÇÕES UNIDAS PARA ALIMENTAÇÃO E AGRICULTURA [FAO], 2013).

Entretanto apenas 5,45\% dos agricultores familiares brasileiros são cooperados (MEDINA et al., 2015). Os números de cooperativas brasileiras ligadas à área rural divergem pouco, conforme os segmentos de representação. O sistema das Organizações das Cooperativas Brasileiras (OCB), segundo dados do Censo de 2012, reconhece 1.528 cooperativas (OCB/GO, 2012). Já a Secretaria Nacional de Economia Solidária (SENAES, 2013) registra a existência de 1.740 cooperativas.

As cooperativas existentes enfrentam o duplo desafio de garantir inserção eficiente nos mercados, ao mesmo tempo em que beneficiam seus associados. Para Amodeo (2001, p. 120): "Seu perfil de empresa associativa, geralmente de alcance regional, gerida democraticamente, por e para seus membros, faz das cooperativas organizações econômicas singulares com problemas e características diferentes dos outros tipos de empresas". Segundo Moreira et al. (2012), a não superação das dificuldades econômicas, sociais e até políticas, podem acarretar falta de competitividade e ainda complexidade gerencial. Dessa forma, a sobrevivência da cooperativa num ambiente globalizado e competitivo está condicionada à sua capacidade de equalizar eficiência econômica e políticas sociais (SCHNEIDER, 2004; DUARTE, 1986).

Para as cooperativas de agricultura familiar, a situação é mais complexa, pois elas têm dificuldades para garantir a produção em escala, a regularidade na oferta de produtos e ainda o quadro de cooperados, composto essencialmente de agricultores com pouca escolaridade e baixa capacidade de investimento (PRADO et al. 2016). Dessa forma, a tomada de decisão, conforme Cechin (2014, p. 486), "pode resultar num padrão de qualidade da produção inferior aos padrões impostos pelas empresas concorrentes".

Existe também a dificuldade de gestão desses empreendimentos que, em grande parte, é realizada de forma amadora se comparada aos padrões de empresas ou mesmo de cooperativas maiores. Para Zylbersztajn (2002, p. 3), "A não separação entre a propriedade e o controle introduz ineficiências que se tornam relevantes quando a organização cresce, seja pelo fato de que a sua atividade original ganha escala ou como decorrência de outros fatores que impliquem maior complexidade gerencial".

Finalmente, além de garantir a inserção comercial e a gestão eficiente, as cooperativas ainda enfrentam o desafio de promover o desenvolvimento de seus associados. Os principais benefícios sociais que as cooperativas conseguem oferecer estão centrados no desenvolvimento econômico baseado na inserção nos mercados e também nas relações sociais que são advindas dos valores de solidariedade e autoajuda, princípios que norteiam o segmento da economia solidária (MOURÃO; ENGLER, 2014; FREITAS; FREITAS, 2013; VASCONCELOS, 2007).

Os dados do Censo do Cooperativismo Goiano mostram a existência de 243 cooperativas em seu quadro de filiadas (OCB - SESCOOP, 2016, p. 32). Já a SENAES informa que, em Goiás, existem 1050 empreendimentos cooperativos. Essa discrepância dos números apresentados entre OCB e Economia Solidária vem corroborar com os estudos de Silva (2006), que questiona "o monopólio de representação no plano associativo".

Segundo dados do Instituto Mauro Borges de Estatísticas e Estudos Socioeconômicos (IMB, 2014), Goiás é a nona economia brasileira com um PIB de R\$179 bilhões (estimativa para 2016), 
que representa 2,9\% do PIB nacional. Sua renda per capita resulta em $\mathrm{R} \$ 26.725,19$. Entre 2010 e 2016, o PIB goiano cresceu, em termos reais, a uma taxa média de 1,6\% ao ano, desempenho acima do nacional, que ficou em $0,29 \%$. Dentre os grandes setores da economia, o de Serviços é o que predomina em Goiás, representando $65,6 \%$ do fluxo de produção. O setor industrial participa com 23,8\% no PIB goiano, e o agropecuário com 10,7\% (IMB, 2014). Embora tenha participação inferior, o setor agropecuário é de grande importância para a economia goiana, pois dele deriva a agroindústria, uma das atividades mais pujantes do estado, quer seja na produção de carnes, derivados de leite e de soja, molhos de tomates, condimentos e outros itens da indústria alimentícia, bem como na produção sucroenergética.

No setor agropecuário, o cooperativismo gera benefícios econômicos. Segundo Gimenes, Gozer e Gozer (2008), as cooperativas têm papel importante na melhoria da distribuição de renda na área rural, uma vez que podem promover a agregação de valor aos produtos agrícolas e aumentar o poder de barganha do produtor rural em mercados relativamente imperfeitos. Para Singer (2007), as ações dos trabalhadores organizados em cooperativas não estariam restritas somente às atividades agrícolas, como também às finanças, à educação, à pesquisa científica e às comunicações, podendo atingir todos os campos de atividades. Segundo Michels (2000), para que uma cooperativa tenha, de fato, condições de oferecer vantagens aos associados, é necessário que ela apresente três características: autoajuda, autorresponsabilidade e autodeterminação democrática.

A pergunta a que se chega é: como essas cooperativas de agricultores familiares conseguirão sobreviver num espaço em que competição no mercado é fundamental ao mesmo tempo em que elas precisam beneficiar socialmente seus cooperados?

O objetivo deste trabalho é contribuir para o melhor entendimento da situação das cooperativas da agricultura familiar do estado de Goiás frente ao contexto atual de mercado competitivo. Especificamente, buscamos:

(1) conhecer a competitividade dos empreendimentos cooperativos, considerando sua gestão, acesso a mercados e viabilidade financeira;

(2) avaliar como os cooperados estão se beneficiando dos empreendimentos no acesso aos mercados, na geração de renda e no fortalecimento das relações sociais.

\section{MATERIAL E MÉTODOS}

Foram selecionadas cinco cooperativas instaladas no estado de Goiás, pelo fato de seu quadro social ser composto, na sua maioria, por agricultores familiares. Denominamos as cooperativas pesquisadas de A, B, C, D e E, uma vez que determinados resultados apresentados nesta pesquisa poderiam comprometer suas relações econômicas frente ao mercado. A proposta da pesquisa foi avaliada pelo Comitê de Ética e Pesquisa (CEP) da Universidade Federal de Goiás.

Foram feitas duas visitas por cooperativa. A primeira visita teve como objetivo a apresentação da proposta de trabalho, buscando o consentimento da cooperativa em participar da pesquisa; a segunda foi para a coleta de dados tanto sobre a cooperativa quanto junto aos cooperados.

A coleta de dados foi iniciada para conhecer os dados de gestão e financeiros da cooperativa. Para cada categoria de análise, foram usados indicadores, conforme o Tabela 1. As entrevistas foram realizadas com representantes do conselho de administração de cada cooperativa, que 
comentaram sobre: (1) como é realizada a gestão do negócio; (2) quais mercados são acessados; e (3) qual a viabilidade financeira dos empreendimentos.

Também foi aplicado um segundo questionário, destinado aos cooperados, buscando entender se essas cooperativas de fato estão beneficiando seu quadro social. Foram considerados os benefícios: (1) nas relações com o mercado; (2) na geração de renda; e (3) nas ações de envolvimento social dos cooperados. Os nomes dos respondentes são fictícios e serão apresentados da seguinte forma: os três cooperados da cooperativa $A$ serão denominados de $A 1, A 2$ e $A 3$; da cooperativa B, serão B1, B2 e B3; da cooperativa C, C1, C2 e C3; da cooperativa D, D1, D2 e D3; e da cooperativa E, E1, E2 e E3.

A realização das entrevistas foi autorizada pela direção das cooperativas e também pelos entrevistados; a escolha dos agricultores entrevistados foi realizada de forma aleatória. Elas aconteceram com um dos diretores nas sedes das cooperativas e nas propriedades rurais com os cooperados. Após a coleta, foi realizada a compilação dos dados, que serviram para fomentar as discussões propostas neste trabalho.

Utilizamos nesta pesquisa o termo "mercado convencional" para as comercializações realizadas pelas cooperativas com o mercado aberto, tradicional, sejam atacadistas, varejistas, supermercados e feiras-livres. Denominamos "mercado institucional" as transações comerciais realizadas por meio das políticas públicas dos programas de comercialização com a agricultura familiar, sendo PAA, PNAE e PNPB.

Tabela 1 - Subtemas, categoria de análises e indicadores de pesquisa

\begin{tabular}{|c|c|c|}
\hline SUBTEMAS & CATEGORIA DE ANÁLISE & INDICADORES \\
\hline \multirow{3}{*}{$\begin{array}{l}\text { Competitividade } \\
\text { do } \\
\text { empreendimento }\end{array}$} & Gestão do negócio & $\begin{array}{l}\text { Número de conselheiros } \\
\text { Periodicidade das reuniões do conselho } \\
\text { Grau de escolaridade } \\
\text { Capacitação em cooperativismo } \\
\text { Apoio técnico para auxiliar na administração }\end{array}$ \\
\hline & Mercados & $\begin{array}{l}\text { Mercados acessados } \\
\text { Formas de comercialização }\end{array}$ \\
\hline & Viabilidade financeira & $\begin{array}{l}\text { Demonstrativo do resultado } \\
\text { Sobra líquida } \\
\text { Balanço patrimonial }\end{array}$ \\
\hline \multirow{3}{*}{$\begin{array}{l}\text { Benefícios aos } \\
\text { cooperados }\end{array}$} & Relações com o mercado & $\begin{array}{l}\text { Produtos comercializados com as cooperativas em } \\
\text { relação ao número de cooperados }\end{array}$ \\
\hline & Geração de renda & $\begin{array}{l}\text { Diferença em comercializar com a cooperativa } \\
\text { Porcentagem da produção destinada à cooperativa }\end{array}$ \\
\hline & $\begin{array}{l}\text { Ações de envolvimento } \\
\text { social }\end{array}$ & $\begin{array}{l}\text { Distinção do grau de envolvimentos dos agricultores } \\
\text { familiares nos seus empreendimentos. }\end{array}$ \\
\hline
\end{tabular}

Fonte: Elaborada pelos autores.

As cooperativas pesquisadas encontram-se em diferentes níveis de organização. As cooperativas A e B são menos estruturadas e têm número menor de cooperados, e as cooperativas C, D e E são mais estruturadas com maior número de cooperados (Tabela 2). As cooperativas consideradas dependentes são aquelas que têm acessado menor quantidade de mercados, trabalham com poucas atividades de comercialização ou ainda estão iniciando suas atividades. Já 
as cooperativas não dependentes são aquelas que já possuem autonomia financeira e acessam variados tipos de mercados.

Tabela 2 - Apresentação das cooperativas: descrição

\begin{tabular}{|l|c|c|c|c|c|}
\hline \multirow{2}{*}{\multicolumn{1}{|c|}{ DESCRIÇão }} & \multicolumn{5}{c|}{ COOPERATIVAS } \\
\cline { 2 - 6 } & A & B & C & D & E \\
\hline Ano de criação & 2002 & 2010 & 2007 & 1998 & 2011 \\
\hline Principal produto & Leite & Soja & Leite & Leite & Soja \\
\hline Tempo de comercialização & 12 anos & 3 anos & 7 anos & 12 anos & 3 anos \\
\hline Mercados institucionais & $\begin{array}{c}\text { Não } \\
\text { dependente }\end{array}$ & Dependente & $\begin{array}{c}\text { Não } \\
\text { dependente }\end{array}$ & $\begin{array}{c}\text { Não } \\
\text { dependente }\end{array}$ & Dependente \\
\hline Número de cooperados & 60 & 60 & 147 & 122 & 621 \\
\hline $\begin{array}{l}\text { Número de agricultores no } \\
\text { município* }\end{array}$ & 2.319 & 5.587 & 2.594 & 4.890 & 12.884 \\
\hline
\end{tabular}

Fonte: Levantamento de campo.

* Instituto Mauro Borges, Estatísticas municipais.

\section{RESULTADOS}

\subsection{Competitividade}

No quesito competitividade, os dados colhidos indicam que as cooperativas estão conseguindo movimentar uma considerável quantia de recursos financeiros (Tabela 3). Mesmo trabalhando com um pequeno número de agricultores, elas são referências nos mercados em que atuam.

Tabela 3 - Demonstrativos financeiros

\begin{tabular}{|c|c|c|c|c|c|}
\hline Cooperativa & A & B* & C & D & E** \\
\hline Resultado 2009 (R\$) & $79.164,72$ & $350.000,00$ & - & $1.504 .528,52$ & - \\
\hline Resultado 2013 (R\$) & $3.063 .172,20$ & $388.000,00$ & $4.362 .413,98$ & $7.897 .109,76$ & $43.069 .060,7$ \\
\hline Patrimônio 2009 (R\$) & - & $20.000,00$ & - & $483.791,83$ & $74.941,93$ \\
\hline Patrimônio 2013 (R\$) & - & - & $613.837,17$ & $1.062 .669,52$ & $232.227,29$ \\
\hline Taxa administrativa & $3 \%$ & $10 \%$ & $6,6 \%$ & $15 \%$ & $10,8 \%$ \\
\hline Financiamento de custeio & Não & Não & SIM & SIM & Não \\
\hline Financiamento investimento & Não & Não & Não & SIM & Não \\
\hline Crescimento cooperados & $150 \%$ & $87,5 \%$ & $4,0 \%$ & $114 \%$ & $2.310 \%$ \\
\hline
\end{tabular}

Fonte: Levantamento de campo.

* Dados do ano de 2010, ano de criação da cooperativa.

** Dados do ano de 2011, ano de criação da cooperativa.

Porém a eficiência da gestão ainda é um desafio em alguns dos empreendimentos, (Tabela 4). Os mecanismos administrativos de rotina, como as reuniões mensais do Conselho de Administração ou mesmo as reuniões semanais da Diretoria, que auxiliariam na agilidade e no avanço desses empreendimentos, ainda são processos amadores ou considerados pouco 
importantes. Verificamos que as cooperativas A e B enfrentam dificuldades estruturantes, dado que a gestão é deficitária em seus processos de decisões, pois elas não são tomadas conforme legislação específica para as cooperativas; o planejamento não é realizado, consequentemente não existe avaliação das ações da direção; e, finalmente, elas não possuem, em seus quadros, equipe técnica qualificada capaz de auxiliar a Direção.

Tabela 4 - Gestão das cooperativas: processos decisórios, planejamento, qualificação técnica

\begin{tabular}{|c|c|c|c|c|c|c|}
\hline & Cooperativa & A & B & C & D & $\mathbf{E}$ \\
\hline \multirow{4}{*}{$\begin{array}{l}\text { Processos } \\
\text { decisórios }\end{array}$} & $\begin{array}{l}\text { Reunião mensal do Conselho de } \\
\text { Administração }\end{array}$ & NÃO & NÃO & SIM & SIM & SIM \\
\hline & Reunião semanal da Diretoria & NÃO & NÃO & NÃO & SIM & SIM \\
\hline & $\begin{array}{l}\text { Tomadas de decisões pelo Conselho de } \\
\text { Administração }\end{array}$ & NÃO & NÃO & SIM & SIM & SIM \\
\hline & $\begin{array}{l}\text { Todos os conselheiros foram } \\
\text { capacitados em gestão }\end{array}$ & NÃO & NÃO & NÃO & SIM & SIM \\
\hline \multirow{3}{*}{ Planejamento } & Realiza planejamento anual de trabalho & NÃO & SIM & SIM & SIM & NÃO \\
\hline & Possui Departamento Comercial & NÃO & NÃO & NÃO & NÃO & NÃO \\
\hline & Avalia as ações da Direção & NÃO & SIM & SIM & SIM & NÃO \\
\hline \multirow{5}{*}{$\begin{array}{l}\text { Qualificação da } \\
\text { equipe técnica }\end{array}$} & $\begin{array}{l}\text { Funcionários com graduação em } \\
\text { Administração }\end{array}$ & NÃO & NÃO & SIM & SIM & SIM \\
\hline & Metas para os funcionários & NÃO & NÃO & NÃO & SIM & NÃO \\
\hline & Possui software de gestão financeira & NÃO & NÃO & SIM & SIM & SIM \\
\hline & Possui equipe técnica & NÃO & NÃO & SIM & SIM & SIM \\
\hline & $\begin{array}{l}\text { Possui infraestrutura oriunda de } \\
\text { recursos públicos }\end{array}$ & NÃO & NÃO & SIM & SIM & NÃO \\
\hline \multicolumn{2}{|l|}{ TOTAL de SIM } & 0 & 2 & 8 & 11 & 7 \\
\hline
\end{tabular}

Fonte: Levantamento de campo.

O mercado das cooperativas $A$ e $B$ está restrito a poucos produtos, com destaque para a cooperativa B, que está concentrada no mercado institucional (Tabela 5). A cooperativa A comercializa apenas o leite para a indústria (embora alguns cooperados comercializem para o PNAE individualmente, sem passar pela cooperativa); já a cooperativa $B$ trabalha com quatro produtos, mas exclusivamente para o PNAE e PNPB. 
Tabela 5 - Mercado convencional, institucional, qualificação dos mercados

\begin{tabular}{|c|c|c|c|c|c|c|}
\hline & Cooperativa & A & B & C & D & $E$ \\
\hline \multirow{5}{*}{$\begin{array}{l}\text { Mercado } \\
\text { convencional }\end{array}$} & \begin{tabular}{|l|} 
Produção/ \\
Comercialização/ \\
serviços
\end{tabular} & Leite & $\begin{array}{c}\text { Frutas, } \\
\text { verduras, } \\
\text { panificados } \\
\text { e soja }\end{array}$ & \begin{tabular}{|c|} 
Leite, \\
melancia, \\
verduras e loja \\
agropecuária
\end{tabular} & $\begin{array}{l}\text { Leite, frutas, verdu- } \\
\text { ras, máquinas agrí- } \\
\text { colas, Assistência } \\
\text { Técnica e Extensão } \\
\text { Rural (ATER), polpa } \\
\text { de frutas }\end{array}$ & $\begin{array}{l}\text { Soja, leite, } \\
\text { frutas e } \\
\text { verduras }\end{array}$ \\
\hline & Indústrias (leite) & $95 \%$ & - & $85 \%$ & $80 \%$ & $10 \%$ \\
\hline & \begin{tabular}{|l|} 
Supermercados - \\
varejistas, lojas
\end{tabular} & - & - & $3 \%$ & $2 \%$ & $0,5 \%$ \\
\hline & Ceasa, atacadistas & - & - & $2 \%$ & $2,32 \%$ & $0,5 \%$ \\
\hline & $\begin{array}{l}\text { Tempo de } \\
\text { comercialização }\end{array}$ & 12 & - & 7 & 11 & 2 \\
\hline \multirow{4}{*}{$\begin{array}{l}\text { Mercado } \\
\text { Institucional }\end{array}$} & PAA & - & - & $5 \%$ & $9,68 \%$ & $0,5 \%$ \\
\hline & PNAE & $5 \%$ & $12 \%$ & $5 \%$ & $6 \%$ & $28,5 \%$ \\
\hline & PNPB & - & $88 \%$ & - & - & $60 \%$ \\
\hline & $\begin{array}{l}\text { Tempo de } \\
\text { comercialização }\end{array}$ & 4 & 3 & 3 & 8 & 3 \\
\hline \multirow{5}{*}{$\begin{array}{l}\text { Qualificação } \\
\text { dos } \\
\text { mercados }\end{array}$} & Agroindústria & - & - & - & SIM & - \\
\hline & Agroecologia & - & - & - & SIM & - \\
\hline & $\begin{array}{l}\text { Auxílio em feiras } \\
\text { municipais }\end{array}$ & - & SIM & SIM & SIM & - \\
\hline & $\begin{array}{l}\text { Rede de } \\
\text { comercialização } \\
\end{array}$ & SIM & - & SIM & SIM & SIM \\
\hline & $\begin{array}{l}\text { Principais } \\
\text { dificuldades }\end{array}$ & $\begin{array}{l}\text { Faltam in- } \\
\text { vestimentos } \\
\text { e capital de } \\
\text { giro }\end{array}$ & Logística & $\begin{array}{l}\text { Capital } \\
\text { de giro, } \\
\text { regularidade } \\
\text { na oferta e } \\
\text { logística }\end{array}$ & $\begin{array}{c}\text { Capital de giro, } \\
\text { regularidade na } \\
\text { oferta e capacidade } \\
\text { técnica }\end{array}$ & $\begin{array}{c}\text { Capital de } \\
\text { giro, escala } \\
\text { de produção, } \\
\text { qualidade } \\
\text { do produto, } \\
\text { logística e } \\
\text { marketing }\end{array}$ \\
\hline
\end{tabular}

Fonte: Levantamento de campo.

Do ponto de vista financeiro, a taxa de administração cobrada pela cooperativa A é muito inferior à taxa das demais, possivelmente comprometendo seu capital de giro. Já a cooperativa B apresenta uma taxa de administração compatível com as demais, porém sofre como o baixo volume negociado, o que dificulta sua viabilidade financeira (Tabela 3).

A não superação desses obstáculos interfere no desenvolvimento das cooperativas. As cooperativas A e B contam com pequeno número de cooperados, pouco volume na comercialização, não possuem quadro de funcionários especializados e, ainda, os membros do Conselho de Administração são pouco capacitados em gestão de cooperativas.

Já as cooperativas C, D e E apresentaram melhores desempenhos competitivos, demonstrados pelos resultados financeiros e pelo crescimento patrimonial, bem como pelo maior volume transacional. As três têm gestão eficiente, com tomadas de decisão dentro do que é preconizado, realizadas semanal e mensalmente. Em particular, a cooperativa E tem uma gestão pragmática voltada para o mercado.

Os dados mostram também que as cooperativas C, D e E estão conseguindo acessar políticas públicas de infraestrutura, sendo que as cooperativas $C$ e $D$ conseguiram melhorar seus 
equipamentos e máquinas através do Programa Territórios Rurais. Além disso, as cooperativas conseguiram, por meio dos seus próprios arranjos, assessoria técnica especializada para a gestão e projetos de desenvolvimento. Ficou evidente que as cooperativas que possuem um maior grau de especialização na gestão, no processo produtivo e na qualidade de seus produtos têm maior propensão a acessar os mercados convencionais.

Referente ao mercado, as três contam com maior diversidade de mercados acessados, atingindo de 7 a 9 produtos diferentes e trabalhando tanto com mercados convencionais quanto institucionais. $\mathrm{O}$ acesso aos mercados institucionais foi oportunizado pelo fato de já terem o básico garantido para os mercados convencionais.

\subsection{Benefícios aos cooperados}

Em relação aos benefícios aos cooperados, os dados revelaram que não existe diferença qualitativa entre as cooperativas. Todas cumprem o papel de apoiar nas relações com o mercado, na geração de renda e no envolvimento social (Tabela 6).

Nas relações com o mercado, todas as cooperativas representam uma alternativa comercial, tanto nos mercados promovidos quanto nos facilitados pelas cooperativas. Isso é refletido na porcentagem da destinação do volume comercializado pelo agricultor pela cooperativa e no incentivo à diversificação da produção dos produtos comercializados. Os diretores e cooperados das cooperativas entendem que são necessárias ações em outras atividades, sejam estas na parte produtiva através de outras culturas, como também na área de agroindústrias processadoras de alimentos, que podem promover a agregação de valor e inserção em diferentes nichos de mercados.

Tabela 6 - Diferença em comercializar com a cooperativa

\begin{tabular}{|c|c|l|}
\hline Cooperativas & Cooperado & Qual a diferença em comercializar com a cooperativa? \\
\hline \multirow{4}{*}{ A } & $\mathbf{1}$ & Preço melhor, mercado garantido, regularidade no pagamento \\
\cline { 2 - 3 } & $\mathbf{2}$ & Preço \\
\cline { 2 - 3 } & $\mathbf{3}$ & Preço \\
\hline \multirow{4}{*}{ B } & $\mathbf{1}$ & - \\
\cline { 2 - 3 } & $\mathbf{2}$ & - \\
\hline \multirow{4}{*}{ C } & $\mathbf{3}$ & Na cooperativa você vende no montante \\
\cline { 2 - 3 } & $\mathbf{1}$ & A diferença é porque a empresa é nossa \\
\cline { 2 - 3 } & $\mathbf{2}$ & Não tem vantagem nenhuma \\
\hline \multirow{4}{*}{ D } & $\mathbf{3}$ & Melhor preço \\
\cline { 2 - 3 } & $\mathbf{1}$ & Garantia na comercialização \\
\cline { 2 - 3 } & $\mathbf{2}$ & Imposto, eliminação do atravessador \\
\hline \multirow{4}{*}{ E } & $\mathbf{3}$ & Preço \\
\cline { 2 - 3 } & $\mathbf{2}$ & Tem bônus na venda da soja \\
\cline { 2 - 3 } & $\mathbf{3}$ & Ela não devolve as mercadorias \\
\hline
\end{tabular}

Fonte: Levantamento de campo.

Na geração de renda, os agricultores entrevistados revelaram que todas as cooperativas apresentam melhores preços que os do mercado local. Elas propiciam a regularidade da compra da produção dos agricultores e a garantia de pagamento dos produtos comercializados, 
cumprindo o papel fundamental de criar concorrência nos mercados locais e evitar a queda dos preços pagos aos produtores.

A melhoria na renda dos agricultores é relevante com o cooperativismo, pois o lucro que antes era auferido pelos atravessadores, na comercialização, agora passa a ser o resultado das sobras da cooperativa, que serão revertidas em preço melhor para o cooperado, ou mesmo em melhoria da infraestrutura da cooperativa. Ainda, os diretores das cooperativas são aqueles que também produzem, convivem e comercializam junto com os demais fornecedores cooperados, portanto têm a real percepção do custo de suas produções.

Os resultados também revelaram que todas cooperativas contribuem para o envolvimento social dos agricultores. Porém foi verificado junto aos cooperados que as cooperativas ainda necessitam trabalhar o seu lado social, no sentido de beneficiar seus sócios, sendo que a maioria dos entrevistados reclamou da distância entre a cooperativa e cooperado e também da carência em trabalhar questões voltadas ao lazer e à participação de jovens e mulheres.

Nessas ações de envolvimento social, observamos uma contraposição referente ao entendimento das atividades realizadas pela cooperativa em favor dos cooperados, uma vez que a direção das cooperativas acredita que está cumprindo com a inclusão social de seus membros. No entanto os cooperados apresentaram um conjunto de demandas para a cooperativa, de forma a se sentirem mais incluídos nas ações e programas realizados pela cooperativa. Apesar das divergências na compreensão do envolvimento social, os resultados revelam que fazer parte da cooperativa movimenta uma rede de relacionamentos que auxiliam na mobilização social nessas comunidades.

\section{DISCUSSÃO}

O presente trabalho trouxe informações a respeito dos potenciais e das dificuldades enfrentadas pelo cooperativismo em Goiás, especificamente pelas cooperativas ligadas à agricultura familiar. O problema proposto neste estudo foi compreender como essas cooperativas conseguem se desenvolver num ambiente que Ihes obriga a ser competitivas na gestão e no acesso aos mercados. A realidade encontrada nesta pesquisa é diversa: existem cooperativas que estão em nível mais avançado e outras que necessitam de melhorias para se desenvolver.

Conforme apresentado por Amodeo (2001) e Duarte (1986), Moreira et al. (2012) e Macedo et al. (2014), as cooperativas pesquisadas neste estudo passam pelas mesmas dificuldades para estabelecer o duplo perfil de empresa cooperativa. Por terem pouca escala, número de cooperados relativamente pequeno, seguido dos baixos volumes comercializados, em determinados casos não conseguem suprir os custos administrativos nem mesmo dar o retorno financeiro necessário, comprometendo a sua função social, que é a de retornar sobras aos cooperados (REDIN, 2015).

Conforme assinalado por Davis e Bialoskorski Neto (2010) sobre gestão nas cooperativas, há ainda outros problemas que foram confirmados como a dificuldade de os indivíduos serem donos e administradores do seu próprio negócio. Existe uma forte tendência, principalmente nas médias e grandes cooperativas, para a contratação de equipe técnica específica para a realização da gestão, ficando à Direção a função de decisão, de acordo com o que já foi apontado por Zylbersztajn (2002), Costa et al. (2012) e Vasconcelos (2007).

Este estudo revelou que dois elementos são fundamentais: a competitividade do empreendimento e o envolvimento social. Os dados mostraram que todas as cooperativas beneficiam os 
sócios e que aquelas com melhor gestão também conseguem uma melhor situação financeira. Não obstante, fazem-se necessários mais estudos direcionados a compreender o caminho que o cooperativismo proposto pelos pensadores da corrente liberal fisiocrata está seguindo, pois, ao que está posto, o cooperativismo de hoje está conduzido pelo capitalismo, de modo que não está atuando na correção das imperfeições do mesmo como previam (SCHNEIDER, 2004; DUARTE, 1986). Em contraposição a esse modelo, o cooperativismo da agricultura familiar e economia solidária (MOURÃO; ENGLER, 2014; SINGER, 2007) tem se aproximado da perspectiva dos socialistas utópicos, pois fundamenta suas estratégias de desenvolvimento de forma equilibrada, buscando reduzir as desigualdades sociais, dinamizar a economia e melhorar a qualidade de vida das populações com estratégias sustentáveis.

\section{CONCLUSÃO}

Esta pesquisa revelou que as cooperativas de Goiás representam uma alternativa de desenvolvimento local, pois contribuem para o fortalecimento das relações sociais no campo. Aquelas que conseguem uma gestão qualificada tornam-se mais competitivas e conseguem uma maior inserção comercial.

A competitividade das cooperativas da agricultura familiar passa tanto pela eficiência comercial do empreendimento quanto por sua capacidade de produzir benefícios para o quadro social. As cooperativas analisadas tiveram diferentes graus de inserção comercial e de eficiência na gestão, mas responderam de forma similar às necessidades dos agricultores cooperados como alternativa de mercado e espaço de fortalecimento das relações sociais. O estudo revelou que as cooperativas C, D e E conseguiram conciliar os interesses econômicos do empreendimento com o benefício ao quadro de sócios. Já as cooperativas $A$ e B beneficiaram o quadro de sócios, mas encontram dificuldades na gestão comercial.

Em relação à eficiência da gestão do empreendimento, os resultados revelaram que algumas delas já estão conseguindo acessar diferentes mercados e têm equipe atuante e capacitada, de modo a garantir a tomada de decisão de forma precisa pelo Conselho Diretivo e pelas assembleias. As cooperativas em estágio inicial podem se fortalecer avançando nesses aspectos, e todas podem ainda se fortalecer tendo pessoal específico para a parte comercial. Algumas cooperativas estão acessando os mercados institucionais de forma adicional ao mercado convencional (geralmente enfocado no leite), permitindo também renda aos agricultores que produzem frutas, hortaliças, doces etc.

\section{REFERÊNCIAS}

ABRAMOVAY, R. Paradigmas do capitalismo agrário em questão. São Paulo: Hucitec/Anpocs/Unicamp, 1992. (Coleção Estudos Rurais).

AMODEO, N. B. P. As cooperativas e os desafios da competitividade. Estudos Sociedade e Agricultura, n. 17, out. 2001.

ASSOCIAÇÃO NACIONAL DE DEFESA VEGETAL [ANDEF]. Agricultura familiar, cooperativas. São Paulo, 2014.

CALDAS, E.; NONATO, R. Compras públicas: estratégia e instrumento para a gestão do desenvolvimento local. Interações, Campo Grande, MS, v. 15, n. 1, p. 13-9, jan./jun. 2014. 
CECHIN, A. Cooperativas brasileiras nos mercados agroalimentares contemporâneos: limites e perspectivas. In: BUAINAIN, A. M.; ALVES, E.; SILVEIRA, J. M.; NAVARRO, Zander (Editores Técnicos). O mundo rural no Brasil do século 21. Brasília, DF: Embrapa, 2014.

COSTA, D. R. M.; CHADDAD, F. R.; FURQUIM DE AZEVEDO, P. Separação Entre Propriedade e Decisão de Gestão nas Cooperativas Agropecuárias Brasileiras. Revista de Economia e Sociologia Rural, Piracicaba, SP, v. 50, n. 2, p. 285-300, abr./jun. 2012.

DAVIS, P.; BIALOSKORSKI NETO, S. Governança e gestão de capital social em cooperativas: uma abordagem baseada em valores. ESAC Economia Solidária e Ação Cooperativa, v. 5, n. 1, jan./jun. 2010.

DUARTE, L. M. G. Capitalismo e cooperativismo no RGS: o cooperativismo empresarial e a expansão do capitalismo no setor rural do Rio Grande do Sul. Porto Alegre: L\&PM/Anpocs, 1986.

FRANÇA, C. G.; DEL GROSSI, M. E.; MARQUES, V. P. M. A. O censo agropecuário 2006 e a agricultura familiar no Brasil. Brasília: MDA, 2009.

FREITAS, A.; FREITAS, A. Interações entre organizações coletivas na promoção do desenvolvimento local. Interações, Campo Grande, MS, v. 14, n. 2, p. 177-88, jul./dez. 2013.

GIMENES, R. M. T.; GOZER, I. C.; GOZER, D. F. A cultura da competição nas sociedades contemporâneas e as ameaças ao modelo atual de gestão financeira das cooperativas agropecuárias brasileiras. Revista de Ciências Empresariais da UNIPAR, Umuarama, PR, v. 9, n. 1 e 2, p. 109-33, jan./dez. 2008.

INSTITUTO MAURO BORGES DE ESTATÍ́STICAS E ESTUDOS SOCIOECONOMICOS (IMB). Banco de dados estatísticos de Goiás 2014. Disponível em: <http://www.imb.go.gov.br/visaogeral/index.html\#sthash. MP5wwHc4.dpuf>. Acesso em: 10 maio 2017.

MACEDO, A.S.; ALCÂNTARA, V. C.; ANTONIALLI, L. M.; MORAIS, G. S. Gestão empresarial e social em cooperativas no espírito santo: uma análise multivariada. In: CONGRESSO SOBER, 52. Apresentação oral... 2014.

MEDINA, G.; ALMEIDA, C.; NOVAES, E.; GODAR, J.; POKORNY, B. Development conditions for family farming: lessons from Brazil. Word Development, v. 74, p. 386-96, out. 2015.

MICHELS, V. Uma contribuição à análise dos princípios de administração financeira aplicados a sociedades cooperativas de produção agrícola. 2000. 166 f. Tese (Doutorado em Controladoria e Contabilidade)Faculdade de Economia, Administração e Contabilidade, Universidade de São Paulo, São Paulo, SP, 2000.

MOREIRA, V. R.; SILVA.; MORAES, E. A.; PROTIL, R. M. O cooperativismo e a gestão dos riscos de mercado: análise de fronteira de eficiência do agronegócio paranaense. Revista de Economia e Sociologia Rural, Piracicaba, SP, v. 50, n. 1, p. 51-68, jan./mar. 2012.

MOURÃO, N.; ENGLER, R. Economia solidária e design social: iniciativas sustentáveis com resíduos vegetais para produção artesanal. Interações, Campo Grande, MS, v. 15, n. 2, p. 329-39, jul./dez. 2014.

ORGANIZAÇÃO DAS COOPERATIVAS BRASILEIRAS SEÇÃO GOIÁS (OCB/GO) - SESCOOP/GO. Censo do Cooperativismo Goiano 2016. Goiás, 2016.

Censo do Cooperativismo Goiano 2012. Goiás, 2012.

ORGANIZAÇÃO DAS NAÇÕES UNIDAS PARA ALIMENTAÇÃO E AGRICULTURA (FAO). Smallholder integration in changing food markets. Roma: FAO, 2013.

PRADO, V.; SANTOS, M.; MEDINA G,; MARTINS, B. Passos da comercialização pelo Programa Nacional de Alimentação Escolar (PNAE) e pelo Programa de Aquisição de Alimentos (PAA). In: Medina, G. (Org.). Agricultura familiar em Goiás: lições de para o assessoramento técnico. Goiânia: Editora UFG, 2016.

REDIN, E. Construção social de mercados: a produção orgânica nos assentamentos do Rio Grande do Sul, Brasil. Interações, Campo Grande, MS, v. 16, n. 1, p. 55-66, jan./jun. 2015.

SCHNEIDER, J. O. Globalización y cooperativismo: la dimensión local y la comunitária. Revista de la Cooperación Internacional, v. 37, n. 1, 2004. 
SECRETARIA NACIONAL DE ECONOMIA SOLIDÁRIA (SENAES). Governo Federal. Boletim Informativo Acontece, edição especial, 2013.

SILVA, M. G.; SILVA, S. P. Para além do acesso: uma análise da relação entre mercados institucionais e empreendimentos de economia solidária no meio rural. In: IPEA. Mercado de Trabalho, 49, nov. 2011.

SILVA, Monika Weronika Dowbor. Possibilidades e limites do cooperativismo pelo prisma de entidades de representação das cooperativas: uma análise comparativa entre a Organização das Cooperativas do Estado de São Paulo (OCESP) e a União e Solidariedade das Cooperativas e Empreendimentos de Economia Social do Brasil (UNISOL/Brasil). 2006. Dissertação (Mestrado em Sociologia)- Universidade de São Paulo, São Paulo, SP, 2006.

SINGER, P.; Economia Solidária e socialismo. In: ORTEGA, A. C.; ALMEIDA FILHO, N. (Org.). Desenvolvimento territorial, segurança alimentar e economia solidária. Campinas, SP: Alínea, 2007. p. 255-60.

VASCONCELOS, T. A. C. A economia solidária na construção social do desenvolvimento territorial. In: ORTEGA, A. C.; ALMEIDA FILHO, N. (Org.). Desenvolvimento territorial, segurança alimentar e economia solidária. Campinas: Alínea, 2007. p. 261-85.

WIGGINS, S.; KIRSTEN, J.; LLAMBí, L. The future of small farms. World Development, v. 38, n. 10, p. 1341-8, 2010.

ZYLBERSZTAJN, D. Quatro estratégias fundamentais para cooperativas agrícolas. São Paulo: FEA-USP/ Pensa, 2002.

\section{Sobre autores:}

Mauro Pereira Santos: Mestre do Programa de Pós-graduação em Agronegócio da Universidade Federal de Goiás, na linha de pesquisa da Agricultura Familiar e professor de Graduação do Centro de Ciências de Itaberaí, GO. E-mail: maurops8@gmail.com

Juliana Rodrigues: Mestre do Programa de Pós-graduação em Agronegócio da Universidade Federal de Goiás, na linha de pesquisa da Agricultura Familiar e professora de Ensino Médio no Colégio Monteiro Lobato de Itapuranga, GO. E-mail: jurrodri@gmail.com

Gabriel Medina: Pós-doutor em Políticas Ambientais pelo Imperial College London (Reino Unido). Professor da Escola de Agronomia da Universidade Federal de Goiás, atuando nos cursos de graduação em Ciências Agrárias e na Coordenação do Programa de Pós-graduação em Agronegócio (linha de pesquisa em Agricultura Familiar).E-mail: gabriel.silva.medina@gmail.com 